\title{
Results of the Adult COVID-19 Lifestyle Matching Study
}

\author{
Rui Zhong ${ }^{1 \dagger}$, Qiong Zhang ${ }^{2 \dagger}$, Yanfang Qiu ${ }^{3}$, Lingxia Chen ${ }^{2 *}$, Jianghua Xie ${ }^{4}$, Yongjun Chen $^{5}$, \\ Yajiao Zou ${ }^{5}$, Lei Zhu ${ }^{4}$, Li Tong ${ }^{6}$, Yanhui Zou ${ }^{1}$, Wei Wang ${ }^{1 *}$ and Yuhua Zhou ${ }^{7}$ \\ ${ }^{1}$ Hunan Cancer Hospital/The Affiliated Cancer Hospital of Xiangya School of Medicine, Central South University, Changsha, \\ China, ${ }^{2}$ Yueyang Central Hospital, Yueyang, China, ${ }^{3}$ Key Laboratory for Molecular Radiation Oncology of Hunan Province, \\ Xiangya Hospital, Hunan, China, ${ }^{4}$ School of Nursing, Hunan University of Chinese Medicine, Changsha, China, ${ }^{5}$ Affiliated Nanhua \\ Hospital, University of South China, Hengyang, China, ${ }^{6}$ The First People's Hospital of Changde City, Changde, China, ${ }^{7}$ Yueyang \\ City Junshan District the People Hospital, Yueyang, China
}

Objective: The aim of our case-control study was to find the influence of lifestyle and comorbidities on COVID-19 susceptibility, identify risk factors and protective factors, and identify ways to encourage people to adopt a healthy lifestyle.

Methods: Patients with COVID-19 were matched with non-COVID-19 participants in a ratio of 1:2. Univariate analysis was performed using the chi-square test, and multivariate analysis was performed using conditional logistic regression.

Results: Multivariate analysis using conditional logistic regression found that alcohol consumption (AC) and a bland diet increased the risk of COVID-19, while college degrees and above, smoking, drinking tea, and exercise, especially walking, significantly reduced the risk of COVID-19.

Conclusion: After removing the effects of demographic factors, the study demonstrated that AC significantly reduced the ability of the body to resist COVID-19 infection. Moreover, following a bland diet increased the susceptibility to COVID-19. Notably, people who drank tea and performed regular exercises, especially walking, were significantly less likely to be infected with COVID-19. College degree or above relative illiteracy is COVID-19 protective factors of infection.

Keywords: smoking, COVID-19, coronavirus, SARS-CoV-2, comorbidity, lifestyle, Alcohol Consumption, betel quid chewing

\section{INTRODUCTION}

Coronavirus disease 2019 (COVID-19) is a respiratory disease caused by the SARS-CoV-2 virus. As of May 30, 2021, COVID-19 has affected nearly 170 million people and resulted in nearly 3.5 million deaths [1]. The immune system is the main entity that defends the body against viral infections, including COVID-19. Since it is still unclear why only some individuals are getting affected with COVID-19, prevention of COVID-19 is essential. Healthy lifestyles have been known to reduce the risk of multiple chronic diseases, including cancer, cardiovascular disease, and diabetes mellitus $(\mathrm{DM})$, and to extend disease-free life expectancy $[2,3]$. Moreover, studies have shown that regular exercise can prevent bacterial and viral infections and enhance the immune functions of the human body $[4,5]$. Food and nutrition have also been shown to be factors affecting the function of the immune system, and many metabolic or chronic diseases are associated with poor dietary habits [6]. Sleep plays a great role in the develop and progression of almost all chronic diseases and is the basis 
for optimal health [7]. Alcocer-bruno et al [8] showed that poor diet, lower physical activity intensity, higher alcohol consumption (AC) and smoking were significantly associated with more HIV risk, and participants with unhealthy lifestyle were twice as likely to be infected with HIV as those with high risk. HCV infection has also been associated with unhealthy lifestyle habits such as shaver sharing, tattooing, body piercing, etc. [9]

Smoking, AC, and betel quid (BQ) chewing are very common unhealthy lifestyle habits worldwide. It has been estimated that there are approximately 1.1 billion daily smokers worldwide, and this number is expected to grow to 1.3 billion by 2025 [10]. Globally, 2.4 billion people consume alcohol [11]. Approximately 1.2-600 million people chew betel nuts, including children, to whom it is freely available for consumption [12]]. Studies have reported that smoking affects both innate and adaptive immunity [13]. Smoking is involved in many immune-produced inflammatory mediators, including pro-inflammatory cytokines and anti-inflammatory cytokines, and has a profound effect on chronic inflammation and systemic immunity [14-18]. Smoking or passive smoking has been shown to increase the risk of infections, such as Middle East Respiratory Syndrome (MERS) $[19,20]$. SARS-CoV-2 MERS-CoV both belong to the same family of coronaviruses; Therefore, the relationship of smoking and COVID-19 has also attracted attention. Similarly, AC also has certain effects on the immune system, and long-term, heavy drinking has been shown to be associated with reduced production of lymphocytes and increased risk of bacterial and viral infections [21]. BQ and its ingredients, especially hydrated lime, causes continuous local stimulation of oral epithelial cells, which can cause chronic inflammation, oxidative stress, and cytokine production [22].

The study by Hamer et al. [23] indicated an unhealthy lifestyle was a risk factor for hospitalization due to COVID-19 and that lifestyle scores were strongly associated with the risk of COVID19 , with a 4.41-fold increase in those with a low lifestyle scores compared with those with the optimal lifestyle. The risk factors for COVID-19 in humans are unknown and susceptible to confounding factors; therefore, it is necessary to further study the impact of lifestyle on the susceptibility to COVID-19. Hence, the aim of our study was to analyze the impact of exercise, diet, sleep, smoking, $\mathrm{AC}$, and $\mathrm{BQ}$ chewing on the prevention of COVID-19 by using a case control study method and thus to provide ways to guide the public to adopt a healthy lifestyle to effectively prevent COVID-19.

\section{METHODS}

\section{Research Setting and Inclusion and Exclusion Criteria}

This case-control study included data from January 2020 to May 2021 from four hospitals (Yueyang Central Hospital; Affiliated Nanhua Hospital, University of South China; The Second People's Hospital of Changde; Junshan District the People Hospital). Inclusion criteria for the case group were: age $\geq 18$ years, Novel Coronavirus nucleic acid was detected by real-time fluorescence RT-PCR and the presence of normal cognitive and understanding abilities. Inclusion criteria for the control group were: Negative nucleic acid test reports of real-time fluorescence RT-PCR Novel Coronavirus within 7 days and the absence of a history of COVID-19 the presence of normal cognitive and understanding abilities. The exclusion criterion was a history of life-threatening or serious physical illness. The permission of the Ethics Committee of Hunan Cancer Hospital (SBQLL-2020094) was obtained for the research. Patients in the case group signed written informed consent forms, whereas oral informed consent was obtained from participants of the control group.

\section{Data Collection}

The demographic data and comorbidities of the case group were collected from the EMR system of the four hospitals, and telephone surveys were conducted with patients to obtain any missing data in the medical records. Substance usage (smoking, $\mathrm{AC}$, and betel chewing) and lifestyle (diet, beverage preference, exercise status, and sleep status) were investigated. Height and weight values were obtained to calculate Body Mass Index (BMI).

The data of patients in the surgical wards of the Yueyang Central Hospital (trauma, urology, gynecology, spinal column, and pediatrics wards) or their family members were collected by trained researchers using questionnaires. A total of 1,032 individuals were surveyed. The completed questionnaires were submitted to the principal investigator for review. Finally, incomplete or invalid questionnaires were excluded and 826 valid questionnaires were retained for the analysis. Patients with COVID-19 and individuals in the control group were basically the same according to sex, marital status, place of residence, educational level, occupation, and age \pm 2 years, and were matched in a ratio of $1: 2$ to be included in the final study groups. Double input of data was performed for analysis.

\section{Variable Definitions and Criteria}

All data were collected in accordance with previous research methods and standards.

(1) Complications: Six common complications that were diagnosed by doctors were collected from the EMR system of the hospitals; these included hypertension (HP), coronary heart disease, hyperlipidemia, renal insufficiency, and cerebral infarction. Control subjects were included by the researchers according to their previous medical history.

(2) AC: history of drinking alcohol of any type for $\geq$ one time per week or continuous drinking for $\geq 1$ year [24].

(3) Smoker: According to WHO (1998), a smoker refers to a person who has smoked continuously or accumulatively for 6 months or more in his life [25]. In this study, data of former smokers who had quit smoking were included in the analysis.

(4) BQ chewing: history of chewing one BQ daily for more than 3 months[26].

\section{Statistical Analysis}

Descriptive statistics were used to analyze demographic data, comorbidities, and lifestyles. Data were input into Excel, using SPSS (version 25.0; SPSS, Chicago, IL, United States). Categorical variables are expressed in terms of frequency and percentage. The 
Table 1 | Univariate analysis of lifestyle between coronavirus disease 2019 patients and matched groups. (Results of the Adult COVID-19 Lifestyle Matching Study, China, 2020-2021.)

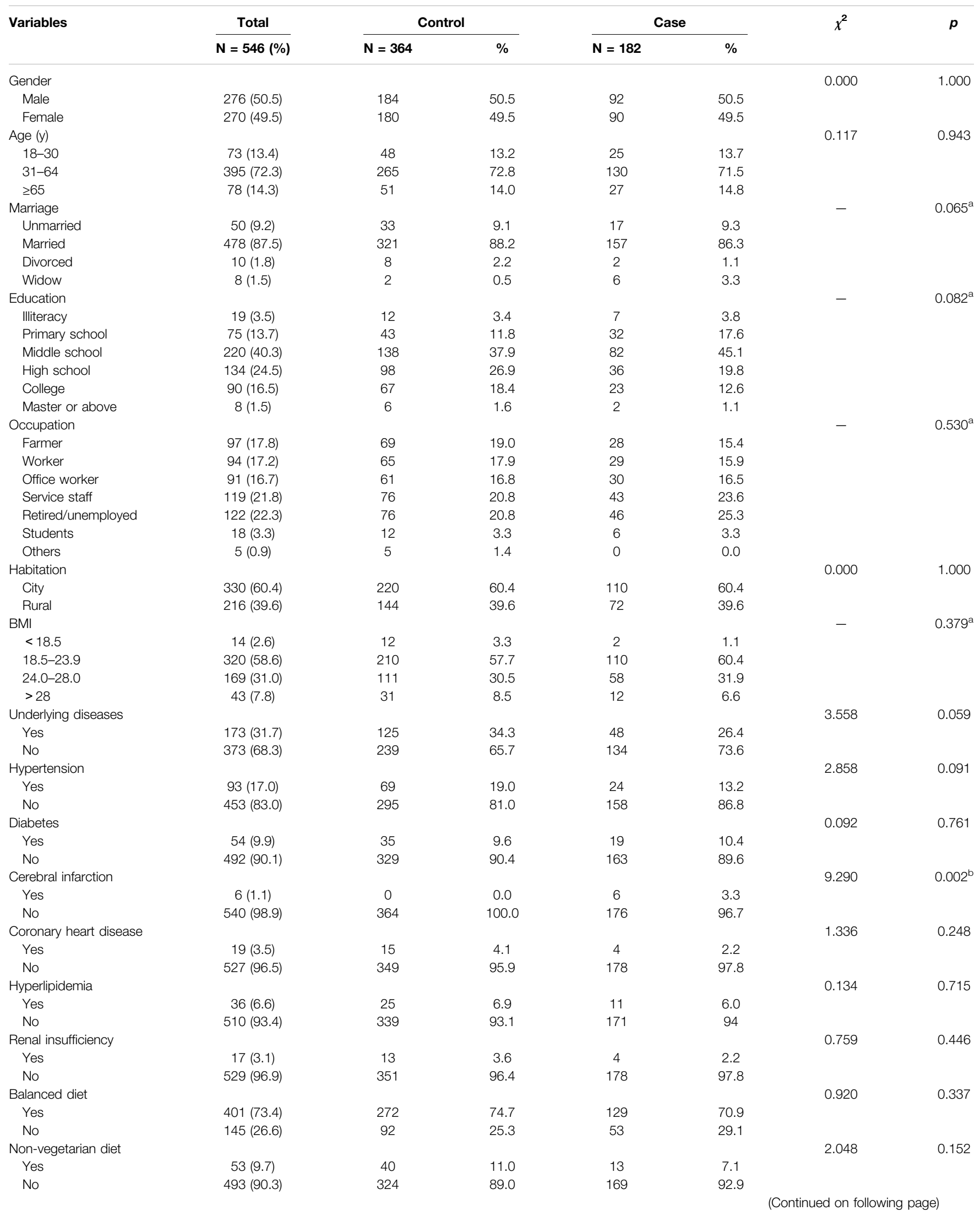


Table 1 | (Continued) Univariate analysis of lifestyle between coronavirus disease 2019 patients and matched groups. (Results of the Adult COVID-19 Lifestyle Matching Study, China, 2020-2021.)

\begin{tabular}{|c|c|c|c|c|c|c|c|}
\hline \multirow[t]{2}{*}{ Variables } & \multirow{2}{*}{$\frac{\text { Total }}{\mathrm{N}=546(\%)}$} & \multicolumn{2}{|c|}{ Control } & \multicolumn{2}{|c|}{ Case } & \multirow[t]{2}{*}{$\chi^{2}$} & \multirow[t]{2}{*}{$p$} \\
\hline & & $\mathbf{N}=364$ & $\%$ & $N=182$ & $\%$ & & \\
\hline Vegetarian diet & & & & & & 5.057 & 0.025 \\
\hline Yes & $53(9.7)$ & 28 & 7.7 & 25 & 13.7 & & \\
\hline No & 493 (90.3) & 336 & 92.3 & 157 & 86.3 & & \\
\hline Bland diet & & & & & & 35.821 & 0.000 \\
\hline Yes & $154(28.2)$ & 73 & 20.1 & 81 & 44.5 & & \\
\hline No & $392(71.8)$ & 291 & 79.9 & 101 & 55.5 & & \\
\hline Prefer spicy diet & & & & & & 0.458 & 0.499 \\
\hline Yes & 111 (20.3) & 77 & 21.2 & 34 & 18.7 & & \\
\hline No & 435 (79.7) & 287 & 78.8 & 148 & 81.3 & & \\
\hline Prefer sweet diet & & & & & & 2.776 & 0.096 \\
\hline Yes & $15(2.7)$ & 13 & 3.6 & 2 & 1.1 & & \\
\hline No & $531(97.3)$ & 351 & 96.4 & 180 & 98.9 & & \\
\hline Carbonated drinks & & & & & & 0.535 & 0.464 \\
\hline Yes & $36(6.6)$ & 26 & 7.1 & 10 & 5.5 & & \\
\hline No & $510(93.4)$ & 338 & 92.9 & 172 & 94.5 & & \\
\hline Fruit juice & & & & & & 0.091 & 0.763 \\
\hline Yes & $23(4.2)$ & 16 & 4.4 & 7 & 3.8 & & \\
\hline No & $523(95.8)$ & 348 & 95.6 & 175 & 96.2 & & \\
\hline functional beverage & & & & & & 0.624 & 0.430 \\
\hline Yes & $10(1.8)$ & 5 & 1.4 & 5 & 2.7 & & \\
\hline No & $536(98.2)$ & 359 & 98.6 & 177 & 97.3 & & \\
\hline Milk tea & & & & & & 0.000 & 1.000 \\
\hline Yes & $15(2.7)$ & 10 & 2.7 & 5 & 2.7 & & \\
\hline No & 531 (97.3) & 354 & 97.3 & 177 & 97.3 & & \\
\hline Coffee & & & & & & 0.308 & 0.579 \\
\hline Yes & $15(2.7)$ & 9 & 2.5 & 6 & 3.3 & & \\
\hline No & 531 (97.3) & 355 & 97.5 & 176 & 96.7 & & \\
\hline Chinese Tea & & & & & & 31.884 & 0.000 \\
\hline Yes & 103 (18.9) & 93 & 25.5 & 10 & 5.5 & & \\
\hline No & $443(81.1)$ & 271 & 74.5 & 172 & 94.5 & & \\
\hline Smoking & & & & & & 4.989 & 0.026 \\
\hline Yes & $137(25.1)$ & 102 & 28.0 & 35 & 19.2 & & \\
\hline No & 409 (74.9) & 262 & 72.0 & 147 & 80.8 & & \\
\hline Alcohol consumption & & & & & & 5.927 & 0.015 \\
\hline Yes & $77(14.1)$ & 42 & 11.5 & 35 & 19.2 & & \\
\hline No & 469 (85.9) & 322 & 88.5 & 147 & 80.8 & & \\
\hline Chewing BQ & & & & & & 0.244 & 0.621 \\
\hline Yes & $35(6.4)$ & 22 & 6.0 & 13 & 7.1 & & \\
\hline No & 511 (93.6) & 342 & 94.0 & 169 & 92.9 & & \\
\hline Exercise & & & & & & 20.900 & 0.000 \\
\hline Yes & 418 (76.6) & 300 & 82.4 & 118 & 64.8 & & \\
\hline No & $128(23.4)$ & 64 & 17.6 & 64 & 35.2 & & \\
\hline Walk & & & & & & 24.621 & 0.000 \\
\hline Yes & $346(63.4)$ & 257 & 70.6 & 89 & 48.9 & & \\
\hline No & $200(36.6)$ & 107 & 29.4 & 93 & 51.1 & & \\
\hline Run & & & & & & 2.024 & 0.155 \\
\hline Yes & $73(13.4)$ & 54 & 14.8 & 19 & 10.4 & & \\
\hline No & 473 (86.6) & 310 & 85.2 & 163 & 89.6 & & \\
\hline Swimming & & & & & & 0.000 & 1.000 \\
\hline Yes & $11(2.0)$ & 7 & 1.9 & 4 & 2.2 & & \\
\hline No & 535 (98.0) & 357 & 98.1 & 178 & 97.8 & & \\
\hline Fitness & & & & & & 1.234 & 0.267 \\
\hline Yes & $15(2.7)$ & 12 & 3.3 & 3 & 1.6 & & \\
\hline No & 531 (97.3) & 352 & 96.7 & 179 & 98.4 & & \\
\hline Dance Aerobics & & & & & & 0.013 & 0.908 \\
\hline Yes & $40(7.3)$ & 27 & 7.4 & 13 & 7.1 & & \\
\hline No & $506(92.7)$ & 337 & 92.6 & 169 & 92.9 & & \\
\hline Yoga & & & & & & 3.680 & $0.055^{b}$ \\
\hline Yes & $10(1.8)$ & 10 & 2.7 & 0 & 0.0 & & \\
\hline No & $536(98.2)$ & 354 & 97.3 & 182 & 100.0 & & \\
\hline
\end{tabular}


Table 1 | (Continued) Univariate analysis of lifestyle between coronavirus disease 2019 patients and matched groups. (Results of the Adult COVID-19 Lifestyle Matching Study, China, 2020-2021.)

\begin{tabular}{|c|c|c|c|c|c|c|c|}
\hline \multirow[t]{2}{*}{ Variables } & \multirow{2}{*}{$\frac{\text { Total }}{\mathrm{N}=546(\%)}$} & \multicolumn{2}{|c|}{ Control } & \multicolumn{2}{|c|}{ Case } & \multirow[t]{2}{*}{$x^{2}$} & \multirow[t]{2}{*}{$p$} \\
\hline & & $N=364$ & $\%$ & $N=182$ & $\%$ & & \\
\hline Sleep pattern & & & & & & 7.551 & 0.056 \\
\hline before 22:00 & $153(28.0)$ & 110 & 30.2 & 43 & 23.6 & & \\
\hline 22:00-24:00 & $316(57.9)$ & 196 & 53.8 & 120 & 65.9 & & \\
\hline after 24:00 & $52(9.5)$ & 39 & 10.7 & 13 & 7.1 & & \\
\hline irregular & $25(4.6)$ & 19 & 5.3 & 6 & 3.4 & & \\
\hline
\end{tabular}

${ }^{a}$ Monte Carlo $\mathrm{p}<0.05$.

${ }^{b}$ Correction for continuity. BMI, body mass index.

chi-square test was used to compare the ratios or constituent ratios of two or more groups. Multivariate conditional logistic regression analysis was used to analyze the influence of COVID-19. Odds ratio (OR), 95\% confidence interval (CI) evaluated via multivariate analysis. Statistical significance was set at $p<0.05$.

\section{RESULTS}

\section{Demographic Characteristics of Participants}

Finally, 182 COVID-19 patients and 364 participants aged 18 years and older were recruited in a 1:2 ratio in the case group and case control group, respectively. There were no statistical differences in gender, age, marriage, education level, occupation, BMI and residence between the two groups. $(p>0.05$, Table 1). The mean age of the participants in the two groups was $47.10 \pm$ 14.15 years and $47.19 \pm 14.19$ years, respectively, and most of the subjects $(395 / 546,72.3 \%)$ were 31-64 years old. Most patients with COVID-19 were having lower education levels, with those with high school education or below accounting for $86.3 \%$ (157/ 182) of the participants. Those who were retired/unemployed and engaged in self-service accounted for $22.3 \%(122 / 546)$ and $21.8 \%$ (119/546), respectively, of the total participants in case and control groups. Three hundred and thirty (60.4\%) participants lived in urban areas and $216(39.6 \%)$ participants resided in rural areas. BMI values ranged from 16.9 to 31.9 , with a median of 23.375 (overweight, $31.0 \%$; obese, $7.8 \%$; and underweight, $2.6 \%$ ).

\section{Comorbidities of Participants in Case and Control Groups}

In this study, $31.7 \%(173 / 546)$ of the total participants had underlying diseases, and $34.3 \%$ (125/364) of the participants in the control group had co-existing diseases, which was higher than the proportion of participants with comorbidities in the case group [26.4\% (48/182)]. HP was present in $17.0 \%$ (93/546) of the total participants. There were no significant differences in proportions of participants with HP, hyperlipidemia, coronary heart disease, and renal insufficiency between case and control groups in univariate analysis. There was statistical difference in the proportion of cerebral infarction between the two groups ( $p=$ 0.002, Table 1).
Dietary and Drinking Habits of Participants Most of the participants in this study followed a balanced diet (73.4\% [401/546]), and few participants followed either a nonvegetarian or vegetarian diet. The proportion of vegetarians $(13.7 \%$ vs. $7.7 \%, p=0.025)$ and followed bland diet $[44.5 \%(81 / 182)$ vs. $20.1 \%(73 / 291), p<0.001]$ between the case group and control group were statistically significant. Only $13.7 \%(75 / 546)$ of the total participants were regular beverage drinkers, and the proportions of participants consuming carbonated drinks, fruit juice, functional drinks, milk tea, and coffee were $6.6 \%, 4.2 \%, 1.8 \%, 2.7 \%$, and $2.7 \%$, respectively. There was no statistical significance in the type of beverages consumed between the two groups ( $p>0.05$, Table 1).

\section{Substance Use Among Participants in Case and Control Groups}

Participants with smoking, AC, and BQ chewing behaviors accounted for $25.1 \%$ (137/546), 14.1\% (77/546), and 6.4\% (35/ 546), respectively, of the total participants. The proportion of alcohol drinkers was significantly higher in the case group than that in the control group [19.2\% (35/182) vs. $11.5 \%(42 / 364), p=$ 0.015 ] The proportion of smokers in the case group $(19.2 \%, 35 / 182)$ was significantly lower than that in the control group $(28.0 \%, 102$ / $364)$, and the difference was statistically significant $(p=0.026)$. There was no statistical significance in BQ chewing behavior between case and control groups ( $7.1 \%$ vs. $6.0 \%, p>0.05$, Table 1$)$.

\section{Exercise and Sleeping Habits of Participants in Case and Control Groups}

In this study, $76.6 \%(418 / 546)$ of the total participants had the habit of exercising, and the proportion of individuals with the habit of exercising was significantly lower in the case group than that in the control group (64.8\% [118/182] vs. 82.4\% [300/364], $p<$ 0.001). The comparison of physical activity (PA) of walking showed that the PA of walking was significantly less among the participants in the case group compared with the individuals in the control group (48.9\% [89/182] vs. $70.6 \%$ [257/364], $p<0.001)$. The proportions of participants following other exercise methods were $10.4 \%$ vs. $14.8 \%$, $2.2 \%$ vs. $1.9 \%, 1.6 \%$ vs. $3.3 \%, 7.1 \%$ vs. $7.4 \%$, and $0.0 \%$ vs. $2.7 \%$ in the case and control groups $(p>0.05)$. Approximately $57.9 \%$ of the participants had the habit of sleeping from 22:00 to $24: 00 ; 28.0 \%$ and 
Table 2 |A multivariate analysis of lifestyle between coronavirus disease 2019 patients and matched groups. (Results of the Adult COVID-19 Lifestyle Matching Study, China, 2020-2021.)

\begin{tabular}{|c|c|c|c|c|c|c|}
\hline Variable & B & S.E & Wald $\chi^{2}$ & $p$ & $\begin{array}{l}\text { Estimated odds } \\
\text { ratio }\end{array}$ & $\begin{array}{c}95 \% \text { confidence } \\
\text { interval }\end{array}$ \\
\hline Cerebral infarction & 11.421 & 120.296 & 0.009 & 0.924 & $91,255.223$ & $0.000-2.271$ \\
\hline Smoking & -1.498 & 0.497 & 9.081 & 0.003 & 0.224 & $0.084-0.592$ \\
\hline Alcohol consumption & 1.837 & 0.507 & 13.117 & 0.000 & 6.275 & 2.323-16.954 \\
\hline Vegetarian diet & 0.170 & 0.474 & 0.128 & 0.720 & 1.185 & $0.468-3.004$ \\
\hline Bland diet & 1.196 & 0.285 & 17.618 & 0.000 & 3.306 & $1.891-5.778$ \\
\hline Drinking tea & -1.128 & 0.427 & 6.969 & 0.008 & 0.324 & $0.140-0.748$ \\
\hline Exercise & 0.131 & 0.493 & 0.071 & 0.790 & 1.140 & $0.434-2.997$ \\
\hline Exercise -Walking & -1.012 & 0.467 & 4.694 & 0.030 & 0.364 & $0.146-0.908$ \\
\hline illiteracy & & & 14.066 & 0.015 & & \\
\hline Primary school & -0.381 & 1.066 & 0.128 & 0.721 & 0.683 & $0.085-5.517$ \\
\hline Middle school & -1.182 & 1.137 & 1.081 & 0.299 & 0.307 & $0.033-2.848$ \\
\hline High school & -2.242 & 1.177 & 3.631 & 0.057 & 0.106 & $0.011-1.066$ \\
\hline College & -3.035 & 1.266 & 5.748 & 0.017 & 0.048 & $0.004-0.575$ \\
\hline Master or above & -3.459 & 1.621 & 4.552 & 0.033 & 0.031 & $0.001-0.755$ \\
\hline
\end{tabular}

9.5\% of the individuals chose to fall asleep before 22:00 and after 24: 00 , respectively, and $4.6 \%$ of the participants had irregular sleeping habits. The difference was not statistically significant $(p=0.056$, Table 1).

\section{Multivariate Factor Analysis}

Multivariate conditional logistic regression analysis was performed with the diagnosis of COVID-19 as the dependent variable; cerebral infarction, vegetarian diet, bland diet, tea drinking, smoking, AC, exercise, walking and education level, as independent variables; $p<$ 0.05 as the inclusion criterion; and $p \geq 0.10$ as the exclusion criterion. The results showed that smokers were less likely to develop COVID-19 (OR $=0.224,95 \% \mathrm{CI}=0.084-0.592 p=$ 0.003). Those who drank alcohol were 6.3 times more likely to develop COVID-19 compared with those who never drank alcohol $(\mathrm{OR}=6.275,95 \% \mathrm{CI}=2.323-16.954, p=0.000)$. Individuals who followed a bland diet had an increased risk of COVID-19 (OR = $3.306,95 \% \mathrm{CI}=1.891-5.778, p=0.000)$. Tea drinking habit $(\mathrm{OR}=$ $0.324,95 \% \mathrm{CI}=0.140-0.748, p=0.008)$ and the habit of exercising of walking ( $\mathrm{OR}=0.364,95 \% \mathrm{CI}=0.146-0.908, p=0.030$ ) were protective factors against COVID-19. Relative illiteracy with college education $(\mathrm{OR}=0.048,95 \% \mathrm{CI}=0.004-0.575, p=0.017)$ and master degree $\mathrm{OR}$ above $(\mathrm{OR}=0.031,95 \% \mathrm{CI}=0.001-0.755, p=$ 0.033) was a protective factor for COVID-19 infection (Table 2).

\section{DISCUSSION}

We performed a matching study according to educational background, occupation, place of residence, marital status, sex, and age to elucidate the relationship between lifestyle and the risk of COVID-19 in adults. There was no difference after statistical analysis $(p<0.05)$.

\section{Physical Activity Is a Protective Factor Against COVID-19}

This study revealed that $76.6 \%$ of the total participants performed regular physical activities, especially walking (63.4\%). Usually, Chinese adults indulge in daily exercises to a greater extent. The number of people who exercised, especially of those who walked, was significantly reduced in the case group compared with the control group (Table 1). Studies have reported that routine PA has a protective effect on the immune system, can enhance the immune response to viral antigens, and reduces the incidence of viral infections [4, 27]. Furthermore, PA can increase the endurance of respiratory muscles or improve the immune response to respiratory viral antigens, and thus prevent respiratory viral infections [28]. Moderate-intensity exercise has a protective effect on respiratory viral infections, while high-intensity exercise may increase the risk of infections [29]. Prolonged and intense exercise can considerably enhance the immune response of the body; however, it can also facilitate infectious processes by viruses, leading to more pathological harm [30]. Simpson et al. [31] had reported that an appropriate extent of PA was beneficial to health and immune functions, and vigorous exercise might lead to an increased risk of disease. Da Silveira et al [32]. confirmed that physical exercise could improve immune functions and prevent COVID-19 in humans. This study suggests that walking may have a potential protective effect against COVID-19 infection. This may be related to the fact that walking can enhance human immunity, and the wide outdoor environment, away from crowded indoor environment, can reduce the chance of close contact with others, thus reducing the risk of infection. Only walking was included as a variable in the multivariate conditional regression analysis in our study; however, other forms of exercise were also found to be beneficial. This may be related to the "J-shaped" hypothesis of physical exercise [34]. Therefore, sedentary behavior should be avoided [33]. Although any PA is beneficial, it should be noted that exercise should be moderate and tolerable, and prolonged and strenuous exercise should be avoided [34]. Compared to other forms of exercise, walking is an easy, free, convenient exercise that can help people fight against COVID-19.

\section{Relationship Between Underlying Diseases and Bland Diet, and COVID-19}

Our study suggested that people who eat a bland diet are at a higher risk of COVID-19. Although multivariate analysis in this 


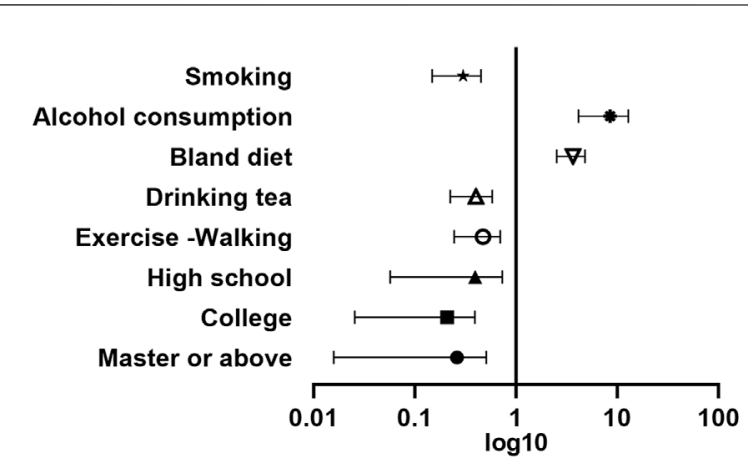

$\begin{array}{cc}\text { OR(95\%Cl) } & P \text { value } \\ 0.224(0.084-0.592) & 0.003 \\ 6.275(2.323-16.954) & 0.000 \\ 3.306(1.891-5.778) & 0.000 \\ 0.324(0.140-0.748) & 0.008 \\ 0.364(0.146-0.908) & 0.030 \\ 0.106(0.011-1.066) & 0.057 \\ 0.048(0.004-0.575) & 0.017 \\ 0.031(0.001-0.755) & 0.033 \\ & \end{array}$

FIGURE 1 | A multivariate analysis of lifestyle between coronavirus disease 2019 patients and matched groups.(Results of the Adult COVID-19 Lifestyle Matching Study, China, 2020-2021.)

study demonstrated that comorbidities were not risk factors for COVID-19. However, we noticed that people with comorbidities followed a bland diet mostly. Approximately 28.2\% (154/546) of the total participants and $34.1 \%(59 / 173)$ of the patients with comorbidities followed a bland diet $(p=0.037)$. In particular, $58.8 \%(10 / 17)$ of the patients with nephropathy had followed a bland diet $(p=0.007)$. However, this study failed to confirm the relationship between underlying diseases and COVID-19. Nutrition can affect the immune system and determine the risk and severity of infections [35]. It has been reported that some nutrients may be associated with the prevention and treatment of COVID-19. These include vitamins such as vitamin $\mathrm{A}, \mathrm{B}, \mathrm{C}, \mathrm{D}$, and $\mathrm{E}$; minerals such as iron, zinc, and selenium; fiber; and essential fatty acids [36]. WHO stress the balanced diet can maintain a strong immune system and avoid or minimize the incidence of chronic and infectious diseases. It has been recommended to follow daily dietary recommendations by WHO to enhance immunity for improved protection against COVID-19 and chronic diseases [37].

\section{Tea Drinking Is a COVID-Protective Factor}

Tea and its bioactive polyphenols have been shown to have many beneficial effects on health [38]]. Results of this study showed that tea drinkers had a significantly decreased COVID-19 risk (OR = $0.324,95 \% \mathrm{CI}=0.140-0.748, p=0.008$ ). This may be related to the antiviral effect of polyphenols in tea [39]. Tea is rich in antioxidants, complex polyphenols, micronutrients, and vitamins. Studies [40] have shown that polyphenols and micronutrients can enhance immunity, which may have strong significance in preventing COVID-19. EGCG (epigallocatechin-3gallate) in green tea extract has been shown to have a significant inhibitory effect on SARS-CoV-2 and other coronavirus infections [41]. EGCG can inhibit the expression of angiotensin-converting enzyme-2 (ACE-2) and transmembrane protease serine 2 (TMPRSS 2) on the cell surface by activating NRF 2, thus inhibiting SARS-CoV-2 infection. Meanwhile, EGCG may also have a protective effect on oxidative stress and cytokine storm started by SARS-CoV-2 [42, 43]. Moreover, catechins have antiinflammatory and potential therapeutic effects against COVID-19 [44]. The micronutrients, vitamins in tea have also been proved to be beneficial in blocking the infection of COVID-19 and reducing
COVID-19 risks [45]. Studies have shown that drinking three cups of tea daily not only has no adverse effects on human health but also is beneficial [46]]. Therefore, tea is recommended as a healthy beverage to help prevent COVID-19. Figure 1.

\section{Smoking and the Risk of COVID-19}

The relationship between smoking and susceptibility to COVID19 has been the focus of scientific debate. Existing studies have shown that the ACE-2 receptor is the entry point of SARS-CoV-2 into host cells and SARS-CoV-2 is more likely to bind and infect human cells than other coronaviruses [47]. However, smoking has been reported to increase the expression of ACE-2 receptors; therefore, smoking is thought to increase the risk of COVID-19 $[48,49]$. Contrary to our prediction, our study showed that smokers had a significantly reduced risk of COVID-19 compared with nonsmokers $(\mathrm{OR}=0.224,95 \% \mathrm{CI}=$ $0.084-0.592 p=0.003)$. This is consistent with the results of the systematic review by Simons D et al [50]. Several other studies have also reported COVID-19 patients had lower smokers rate than those the public $[51,52]$. The smoker rate of COVID-19 patients in China accounts for only one-fourth of the proportion of smokers among the public in China [53, 54]. This study showed COVID-19 patients smoking rate was $19.2 \%(35 / 182)$, which also was significantly lower than the $28.0 \%(102 / 364)$ of the control group. Results from a study involving 175 countries also showed that globally, the percentage of smokers in a population is inversely correlated with the incidence of COVID-19 [55]. Some studies suggest that this may be related to nicotine, a component of tobacco $[53,56]$. Nicotine is a cholinergic agonist, which has anti-inflammatory effects and can regulate the immune response of the body $[57,58]$. Nicotine suppresses the production of proinflammatory cytokines in smokers may render their immune responses more tolerable than those in patients who have never smoked [57, 59]. Moreover, nitric oxide (NO) generated during smoking is involved in maintaining airway dilation and filtration before entering the lungs. However, NO has been shown to inhibit the replication and entry of SARS-CoV-2 into body cells [60]. While these mechanisms may indicate the potential therapeutic effects of nicotine, tobacco smoke is known to be a complex mixture of over 5,000 chemicals, carcinogens, or toxins [61]. Smoking not only affects one's overall health but also 
damages almost every organ in the body $[62,63]$. Even though smokers may have lower incidence rates of COVID-19 than those in normal people, the adverse health effects of smoking surpass the benefits [56]. Therefore, the WHO advises the public to quit smoking and to be cautious about smoking as a method of protection against COVID-19.

\section{AC Significantly Increases the Risk of COVID-19}

Our study found that AC also increased the risk of COVID-19, and the risk of COVID-19 in those who drank alcohol was 6.3 times higher than that in those who never drank alcohol $(\mathrm{OR}=6.275$, $95 \% \mathrm{CI}=2.323-16.954, p=0.000)$, consistent with the results of Bailey et al [64]. There is also evidence that $\mathrm{AC}$ increases the risk of bacterial pneumonia, tuberculosis, respiratory syncytial virus (RSV) infection, and acute respiratory distress syndrome (ARDS) [65]. This may be related to the damage to the immune system caused by alcohol [66]. The immune system protects the host against pathogens and unwanted immune responses to the body, including innate and adaptive immunity. Alcohol has been shown to interfere with both types of immunity $[67,68]$. Alcohol also changes the balance and interaction between the immune system and the microbiome of the host. There is evidence that any level of AC is not good for your health and that even one drink can damage your health $[69,70]$. However, Ahmed et al. [71] reported that during the period of social isolation during the COVID-19 outbreak, the incidence of alcohol use disorders (AUDs) in Hubei province increased 10 times more than that in other provinces with fewer restrictions. In Britain, a study reported that one in five people had consumed increased amounts of alcohol since incarceration [72]]. It is important to recognize that AC increases the risk of COVID-19, and people should be encouraged to avoid or reduce AC to prevent COVID-19.

\section{College Degree or Above is a Protective Factor for COVID-19 Infection}

Our case-control study suggested that education levels were associated with COVID-19 susceptibility. College degree or above relative illiteracy is COVID-19 protective factors of infection; this is consistent with the findings of Hawkins et al. [73]. People with higher education may pay more attention to the epidemic situation and have stronger protection awareness, while those with lower education may have a lowered ability to acquire health knowledge and take protective measures. Zhong et al. [74] showed that there was a significant positive correlation between education level and COVID-19 knowledge score; the higher the COVID-19 knowledge score, the lower the likelihood of negative attitudes and potentially dangerous practices toward COVID-19 prevalence.

\section{Limitations}

First, in this study, a convenience sampling method was adopted for the matched samples of patients or their family members from the surgical wards of a general hospital. Second, although cerebral infarction was included in the multivariate regression analysis, there were only six cases of cerebral infarction in the case group; therefore, the sample size was too small. These two factors may have caused the bias of the respective results. Future researches based on these limitations are required.

\section{Conclusion}

After controlling for education, occupation, place of residence, marital status, sex and age, our study found that physical activity, particularly regular walking and drinking more tea, college degree or above was associated with a reduced risk of COVID-19 infection, while drinking any type of alcohol significantly increased the risk of COVID-19. Although this case-control study showed that smokers had a lower rate of incidence of COVID-19 than that among non-smokers, the underlying mechanism could not be elucidated; therefore, further studies should be conducted. Previous studies have confirmed that smoking is harmful; therefore, smoking should be discouraged and smokers should be encouraged to quit smoking.

\section{ETHICS STATEMENT}

The studies involving human participants were reviewed and approved by the Ethics Committee of Hunan Cancer Hospital (Approval Number: SBQLL-2020-094, Jane, 2020). Oral informed consent was obtained from all subjects involved in the study.

\section{AUTHOR CONTRIBUTIONS}

RZ contributed to conceptualization, methodology, validation, writing the original draft, and reviewing and editing the manuscript. QZ contributed to conceptualization, data curation, investigation, resources, and writing the original draft. YQ contributed to formal analysis, methodology. LC and JX contributed to supervision and validation. YC contributed to reviewing and editing the manuscript. YajZ and YZh contributed to data curation and resources. LZ contributed to data curation. LT contributed to the formal analysis. YanZ contributed to conceptualization, funding acquisition, and project administration. WW contributed to project administration, supervision, and validation.

\section{FUNDING}

This research was funded by Hunan Provincial Bureau of Science and Technology (Grant Number: 2021ZK4076, 2021ZK4078); Changsha Science and Technology Bureau in China (Grant Number: kq1901085); Affiliated Nanahua Hospital, University of South China (Grant Number: 2020SK3040).

\section{CONFLICT OF INTEREST}

The authors declare that the research was conducted in the absence of any commercial or financial relationships that could be construed as a potential conflict of interest. 


\section{REFERENCES}

1. WHO.2021 WHO Coronavirus Disease (COVID-19) Dashboard. Available online: https://covid19.who.int/[(accessed on 30 May 2021)]]

2. Nyberg ST, Singh-Manoux A, Pentti J, Madsen I, Kivimki M. Association of Healthy Lifestyle with Years Lived without Major Chronic Diseases. JAMA Intern Med (2020) 180(5):760-8. doi:10.1001/jamainternmed.2020. 0618

3. Li Y, Schoufour J, Wang DD, Dhana K, Hu FB. Healthy Lifestyle and Life Expectancy Free of Cancer, Cardiovascular Disease, and Type 2 Diabetes: Prospective Cohort Study. BMJ (2020) 368:16669. doi:10.1136/bmj.16669

4. Campbell JP, Turner JE. Debunking the Myth of Exercise-Induced Immune Suppression: Redefining the Impact of Exercise on Immunological Health across the Lifespan. Front Immunol (2018) 9:648. doi:10.3389/fimmu.2018. 00648

5. Scheffer DDL, Latini A. Exercise-induced Immune System Response: Antiinflammatory Status on Peripheral and central Organs. Biochim Biophys Acta Mol Basis Dis (2020) 1866(10):165823. doi:10.1016/j.bbadis.2020.165823

6. Childs CE, Calder PC, Miles EA. Diet Immune Funct Nutrients (2019) 11(8): 1933. doi:10.3390/nu11081933

7. von Ruesten A, Weikert C, Fietze I, Boeing H. Association of Sleep Duration with Chronic Diseases in the European Prospective Investigation into Cancer and Nutrition (EPIC)-Potsdam Study. PLoS One (2012) 7(1):e30972. doi:10. 1371/journal.pone.0030972

8. Alcocer-Bruno C, Ferrer-Cascales R, Ruiz-Robledillo N, Sánchez-SanSegundo M, Zaragoza-Martí A. Personal and Lifestyle Determinants of HIV Transmission Risk in Spanish University Students. Int J Environ Res Public Health (2020) 17(22):8332. doi:10.3390/ijerph17228332

9. Sohn HS, Kim JR, Ryu SY, Lee YJ, Lee MJ, Min HJ, et al. Risk Factors for Hepatitis C Virus (HCV) Infection in Areas with a High Prevalence of HCV in the Republic of Korea in 2013. Gut Liver (2016) 10(1):126-32. doi:10.5009/ gnl14403

10. Bilano V, Gilmour S, Moffiet T, Espaignet D, Stevens GA, Commar A, et al. Global Trends and Projections for Tobacco Use, 1990-2025: an Analysis of Smoking Indicators from the WHO Comprehensive Information Systems for Tobacco Control. Lancet (2015) 385(9972):966-76. doi:10.1016/S01406736(15)60264-1

11. Testino G. Are Patients with Alcohol Use Disorders at Increased Risk for Covid-19 Infection. Alcohol Alcohol (2020) 55(4):344-6. doi:10.1093/alcalc/ agaa037

12. Gupta PC, Warnakulasuriya S. Global Epidemiology of Area Nut Usage. Addict Biol (2002) 7(1):77-83. doi:10.1080/13556210020091437

13. Qiu F, Liang CL, Liu H, Zeng YQ, Hou S, Huang S, et al. Impacts of Cigarette Smoking on Immune Responsiveness: Up and Down or Upside Down. Oncotarget (2017) 8(1):268-84. doi:10.18632/oncotarget.13613

14. Duffney PF, Embong AK, McGuire CC, Thatcher TH, Phipps RP, Sime PJ. Cigarette Smoke Increases Susceptibility to Infection in Lung Epithelial Cells by Upregulating Caveolin-dependent Endocytosis. PLoS One (2020) 15(5): e0232102. doi:10.1371/journal.pone.0232102

15. Duffney PF, M Cc Arthy CE, Aitor N, Thatcher TH, Luis MS, Phipps RP, et al. Cigarette Smoke Dampens Antiviral Signaling in Small Airway Epithelial Cells by Disrupting TLR3 Cleavage. Am J Physiol Lung Cel Mol Physiol (2018) 314(3):L505-L513. doi:10.1152/ajplung.00406.2017

16. Qin H, Huang G, Gao F, Huang B, Wang D, Hu X, et al. Diminished Stimulator of Interferon Genes Production with Cigarette Smoke-Exposure Contributes to Weakened Anti-adenovirus Vectors Response and Destruction of Lung in Chronic Obstructive Pulmonary Disease Model. Exp Cel Res (2019) 384(1): 111545. doi:10.1016/j.yexcr.2019.111545

17. Staudt MR, Salit J, Kaner RJ, Hollmann C, Crystal RG. Altered Lung Biology of Healthy Never Smokers Following Acute Inhalation of E-Cigarettes. Respir Res (2018) 19(1):78. doi:10.1186/s12931-018-0778-z

18. Perricone C, Versini M, Ben-Ami D, Gertel S, Watad A, Segel MJ, et al. Smoke and Autoimmunity: The Fire behind the Disease. Autoimmun Rev (2016) 15(4):354-74. doi:10.1016/j.autrev.2016.01.001

19. Lawrence H, Hunter A, Murray R, Lim WS, McKeever T. Cigarette Smoking and the Occurrence of Influenza - Systematic Review. J Infect (2019) 79(5): 401-6. doi:10.1016/j.jinf.2019.08.014
20. Park JE, Jung S, Kim A, Park JE. MERS Transmission and Risk Factors: a Systematic Review. BMC Public Health (2018) 18(1):574. doi:10.1186/s12889018-5484-8

21. Barr T, Helms C, Grant K, Messaoudi I. Opposing Effects of Alcohol on the Immune System. Prog Neuropsychopharmacol Biol Psychiatry (2016) 65: 242-51. doi:10.1016/j.pnpbp.2015.09.001

22. IARC Working Group on the Evaluation of Carcinogenic Risks to Humans. Personal Habits and Indoor Combustions. Volume 100 E. A Review of Human Carcinogens. IARC Monogr Eval Carcinog Risks Hum (2012) 100(Pt E):1-538.

23. Hamer M, Kivimäki M, Gale CR, Batty GD. Lifestyle Risk Factors, Inflammatory Mechanisms, and COVID-19 Hospitalization: A Community-Based Cohort Study of 387,109 Adults in UK. Brain Behav Immun (2020) 87:184-7. doi:10.1016/j.bbi.2020.05.059

24. Lee $\mathrm{CH}, \mathrm{Wu}$ DC, Wu IC, Goan YG, Lee JM, Chou SH, et al. Genetic Modulation of ADH1B and ALDH2 Polymorphisms with Regard to Alcohol and Tobacco Consumption for Younger Aged Esophageal Squamous Cell Carcinoma Diagnosis. Int J Cancer (2009) 125(5):1134-42. doi:10.1002/ijc. 24357

25. World Health Organization. Guidelines for Controlling and Monitoring the Tobacco Epidemic. World Health Organ Libr Cataloguing Publ Data (1998):76-8.

26. Xiao FY, Zhao WZ, Wang F, Gui ZJ, Yuan S. Study on the Impact of Betel Nut Chewing on the Health Status of Oral Mucosa in Xiangtan City and Changde City in Hunan Province. Pract Prev Med (2014) 24(2):155-9. doi:10.3969/j. issn.1006-3110.2014.02.009

27. Dorneles GP, Dos Passos A, Romão P, Peres A. New Insights about Regulatory $\mathrm{T}$ Cells Distribution and Function with Exercise: The Role of Immunometabolism. Curr Pharm Des (2020) 26(9):979-90. doi:10.2174/ 1381612826666200305125210

28. McKenzie DC. Respiratory Physiology: Adaptations to High-Level Exercise. $\mathrm{Br}$ J Sports Med (2012) 46(6):381-4. doi:10.1136/bjsports-2011-090824

29. Nieman DC. Exercise, Upper Respiratory Tract Infection, and the Immune System. Med Sci Sports Exerc (1994) 26(2):128-39. doi:10.1249/00005768199402000-00002

30. Martin SA, Pence BD, Woods JA. Exercise and Respiratory Tract Viral Infections. Exerc Sport Sci Rev (2009) 37(4):157-64. doi:10.1097/JES. 0b013e3181b7b57b

31. Simpson RJ, Campbell JP, Gleeson M, Krüger K, Nieman DC, Pyne DB, et al. Can Exercise Affect Immune Function to Increase Susceptibility to Infection. Exerc Immunol Rev (2020) 26:8-22.

32. da Silveira MP, da Silva Fagundes KK, Bizuti MR, Starck É, Rossi RC, de Resende E, et al. Physical Exercise as a Tool to Help the Immune System against COVID-19: an Integrative Review of the Current Literature. Clin Exp Med (2021) 21(1):15-28. doi:10.1007/s10238-020-00650-3

33. Pitanga FJG, Beck CC, Pitanga CPS. Physical Activity And Reducing Sedentary Behavior During The Coronavirus Pandemic. Atividade Física e Redução Do Comportamento Sedentário durante a Pandemia Do Coronavírus. Arq Bras Cardiol (2020) 114(6):1058-60. doi:10.36660/abc.20200238

34. Jakobsson J, Malm C, Furberg M, Ekelund U, Svensson M. Physical Activity during the Coronavirus (COVID-19) Pandemic: Prevention of a Decline in Metabolic and Immunological Functions. Front Sports Act Living (2020) 2:57. doi:10.3389/fspor.2020.00057

35. Gasmi A, Noor S, Tippairote T, Dadar M, Menzel A, Biørklund G. Individual Risk Management Strategy and Potential Therapeutic Options for the COVID19 Pandemic. Clin Immunol (2020) 215:108409. doi:10.1016/j.clim.2020. 108409

36. Zhang L, Liu Y. Potential Interventions for Novel Coronavirus in China: A Systematic Review. J Med Virol (2020) 92(5):479-90. doi:10.1002/jmv.25707

37. WHO.World Health 2020 Organization Nutrition Advice for Adults during the COVID-19 Outbreak. Available from: http://www.emro.who.int/nutrition/ nutrition-infocus/nutrition-advice-for-adults-during-the-covid-19-outbreak. html 2020 accessed on 19062020

38. Hayat K, Iqbal H, Malik U, Bilal U, Mushtaq S. Tea and its Consumption: Benefits and Risks. Crit Rev Food Sci Nutr (2015) 55(7):939-54. doi:10.1080/ 10408398.2012.678949

39. Mhatre S, Srivastava T, Naik S, Patravale V. Antiviral Activity of green tea and Black tea Polyphenols in Prophylaxis and Treatment of COVID-19. A Review Phytomedicine (2021) 85:153286. doi:10.1016/j.phymed.2020.153286 
40. Cena H, Chieppa M. Coronavirus Disease (COVID-19-SARS-CoV-2) and Nutrition: Is Infection in Italy Suggesting a Connection? Front Immunol (2020) 11:944. doi:10.3389/fimmu.2020.00944

41. Henss L, Auste A, Schürmann C, Schmidt C, von Rhein C, Mühlebach MD, et al. The green tea Catechin Epigallocatechin Gallate Inhibits SARS-CoV-2 Infection. J Gen Virol (2021)(4) 102. doi:10.1099/jgv.0.00157410.1099/jgv.0. 001574

42. Zhang Z, Zhang X, Bi K, He Y, Yan W, Yang CS, et al. Potential Protective Mechanisms of green tea Polyphenol EGCG against COVID-19 [published Online Ahead of Print, 2021 May 25]. Trends Food Sci Technol (2021). doi:10. 1016/j.tifs.2021.05.023

43. Cuadrado A, Pajares M, Benito C, Jiménez-Villegas J, Escoll M, FernándezGinés R, et al. Can Activation of NRF2 Be a Strategy against COVID-19? Trends Pharmacol Sci (2020) 41(9):598-610. doi:10.1016/j.tips.2020.07.003

44. hourasia M, Koppula PR, Battu A, Ouseph MM, Singh AK. EGCG, a Green Tea Catechin, as a Potential Therapeutic Agent for Symptomatic and Asymptomatic SARS-CoV-2 Infection. Molecules (2021) 26(5):1200. doi:10. 3390/molecules 26051200

45. Keflie TS, Biesalski HK. Micronutrients and Bioactive Substances: Their Potential Roles in Combating COVID-19. Nutrition (2021) 84:111103. doi:10.1016/j.nut.2020.111103

46. Karak T, Kutu FR, Nath JR, Sonar I, Paul RK, Boruah RK, et al. Micronutrients (B, Co, Cu, Fe, Mn, Mo, and $\mathrm{Zn}$ ) Content in Made tea (Camellia Sinensis L.) and tea Infusion with Health prospect: A Critical Review. Crit Rev Food Sci Nutr (2017) 57(14):2996-3034. doi:10.1080/10408398.2015.1083534

47. Wrapp D, Wang N, Corbett KS, Goldsmith JA, Hsieh CL, Abiona O, et al. Cryo-EM Structure of the 2019-nCoV Spike in the Prefusion Conformation. Science (2020) 367(6483):1260-3. doi:10.1126/science.abb2507

48. Smith JC, Sausville EL, Girish V, Yuan ML, Vasudevan A, John KM, et al. Cigarette Smoke Exposure and Inflammatory Signaling Increase the Expression of the SARS-CoV-2 Receptor ACE2 in the Respiratory Tract. Dev Cel (2020) 53(5):514-29. e3. doi:10.1016/j.devcel.2020.05.012

49. Leung JM, Yang CX, Tam A, Shaipanich T, Hackett TL, Singhera GK, et al. ACE-2 Expression in the Small Airway Epithelia of Smokers and COPD Patients: Implications for COVID-19. Eur Respir J (2020) 55(5):2000688. doi:10.1183/13993003.00688-2020

50. Simons D, Shahab L, Brown J, Perski O. The Association of Smoking Status with SARS-CoV-2 Infection, Hospitalization and Mortality from COVID-19: a Living Rapid Evidence Review with Bayesian Meta-Analyses (Version 7). Addiction (2021) 116(6):1319-68. doi:10.1111/add.15276

51. Tajlil A, Ghaffari S, Pourafkari L, Mashayekhi S, Roshanravan N. Nicotine and Smoking in the COVID-19 Era. J Cardiovasc Thorac Res (2020) 12(2):136-9. doi:10.34172/jcvtr.2020.22

52. Miyara M, Tubach F, Pourcher V, Morelot-Panzini C, Amoura Z. Low Incidence of Daily Active Tobacco Smoking in Patients with Symptomatic COVID-19. Qeios (2020). doi:10.32388/WPP19W

53. Farsalinos K, Barbouni A, Niaura R. Systematic Review of the Prevalence of Current Smoking Among Hospitalized COVID-19 Patients in China: Could Nicotine Be a Therapeutic Option? Intern Emerg Med (2020) 15(5):845-52. doi:10.1007/s11739-020-02355-7

54. Emami A, Javanmardi F, Pirbonyeh N, Akbari A. Prevalence of Underlying Diseases in Hospitalized Patients with COVID-19: a Systematic Review and Meta-Analysis. Arch Acad Emerg Med (2020) 8(1):e35.

55. Iyanda AE, Adeleke R, Lu Y, Osayomi T, Adaralegbe A, Lasode M, et al. A Retrospective Cross-National Examination of COVID-19 Outbreak in 175 Countries: a Multiscale Geographically Weighted Regression Analysis (January 11-June 28, 2020). J Infect Public Health (2020) 13(10):1438-45. doi:10.1016/j.jiph.2020.07.006

56. Usman MS, Siddiqi TJ, Khan MS, Patel UK, Shahid I, Ahmed J, et al. Is There a Smoker's Paradox in COVID-19? BMJ Evid Based Med (2021) 26(6):279-84. doi:10.1136/bmjebm-2020-111492
57. Wang H, Yu M, Ochani M, Amella CA, Tanovic CA, Susarla M, et al. Nicotinic Acetylcholine Receptor Alpha7 Subunit Is an Essential Regulator of Inflammation. Nature (2003) 421(6921):384-8. doi:10.1038/nature01339

58. Jenkins BJ, Grail D, Nheu T, Najdovska M, Wang B, Waring P, et al. Hyperactivation of Stat3 in Gp130 Mutant Mice Promotes Gastric Hyperproliferation and Desensitizes TGF-Beta Signaling. Nat Med (2005) 11(8):845-52. doi:10.1038/nm1282

59. Garufi G, Carbognin L, Orlandi A, Tortora G, Bria E. Smoking Habit and Hospitalization for Severe Acute Respiratory Syndrome Coronavirus 2 (SARSCoV-2)-Related Pneumonia: The Unsolved Paradox behind the Evidence. Eur J Intern Med (2020) 77:121-2. doi:10.1016/j.ejim.2020.04.042

60. Akerström S, Mousavi-Jazi M, Klingström J, Leijon M, Lundkvist A, Mirazimi A. Nitric Oxide Inhibits the Replication Cycle of Severe Acute Respiratory Syndrome Coronavirus. J Virol (2005) 79(3):1966-9. doi:10.1128/JVI.79.3. 1966-1969.2005

61. Shastri MD, Shukla SD, Chong WC, Kc R, Dua K, Patel RP, et al. Smoking and COVID-19: What We Know So Far. Respir Med (2021) 176:106237. doi:10. 1016/j.rmed.2020.106237

62. National Center for Chronic Disease Prevention and Health Promotion (US). Office on Smoking and Health. The Health Consequences of Smoking-50 Years of Progress: A Report of the Surgeon General. Atlanta (GA): Centers for Disease Control and Prevention (US (2014).

63. Haddad C, Bou Malhab S, Sacre H, Salameh P. Smoking and COVID-19: A Scoping Review. Tob Use Insights (2021) 14:1179173X21994612. doi:10.1177/ 1179173X21994612

64. Bailey KL, Samuelson DR, Wyatt TA. Alcohol Use Disorder: A Pre-existing Condition for COVID-19? Alcohol (2021) 90:11-7. doi:10.1016/j.alcohol.2020. 10.003

65. Szabo G, Saha B. Alcohol's Effect on Host Defense. Alcohol Res (2015) 37(2): $159-70$.

66. Pasala S, Barr T, Messaoudi I. Impact of Alcohol Abuse on the Adaptive Immune System. Alcohol Res (2015) 37(2):185-97.

67. Burton R, Sheron N. No Level of Alcohol Consumption Improves Health. Lancet (2018) 392(10152):987-8. doi:10.1016/S0140-6736(18)31571-X

68. Braillon A, Wilson M. Does Moderate Alcohol Consumption Really Have Health Benefits? BMJ (2018) 362:k3888. doi:10.1136/bmj.k3888

69. Ahmed MZ, Ahmed O, Aibao Z, Hanbin S, Siyu L, Ahmad A. Epidemic of COVID-19 in China and Associated Psychological Problems. Asian J Psychiatr (2020) 51:102092. doi:10.1016/j.ajp.2020.102092

70. The Lancet Gastroenterology Hepatology. Drinking Alone: COVID-19, Lockdown, and Alcohol-Related Harm. Lancet Gastroenterol Hepatol (2020) 5(7):625. doi:10.1016/S2468-1253(20)30159-X

71. Hawkins RB, Charles EJ, Mehaffey JH. Socio-economic Status and COVID-19Related Cases and Fatalities. Public Health (2020) 189:129-34. doi:10.1016/j. puhe.2020.09.016

72. Zhong BL, Luo W, Li HM, Zhang QQ, Liu XG, Li WT, et al. Knowledge, Attitudes, and Practices towards COVID-19 Among Chinese Residents during the Rapid Rise Period of the COVID-19 Outbreak: a Quick Online CrossSectional Survey. Int J Biol Sci (2020) 16(10):1745-52. doi:10.7150/ijbs.45221

73. Simet SM, Sisson JH. Alcohol's Effects on Lung Health and Immunity. Alcohol Res (2015) 37(2):199-208.

74. Sharma A, Kroumpouzos G, Lotti T, Goldust M. COVID-19 and Alcohol Use. Drug Alcohol Rev (2021) 40(4):683-4. doi:10.1111/dar.13163

Copyright (C) 2022 Zhong, Zhang, Qiu, Chen, Xie, Chen, Zou, Zhu, Tong, Zou, Wang and Zhou. This is an open-access article distributed under the terms of the Creative Commons Attribution License (CC BY). The use, distribution or reproduction in other forums is permitted, provided the original author(s) and the copyright owner(s) are credited and that the original publication in this journal is cited, in accordance with accepted academic practice. No use, distribution or reproduction is permitted which does not comply with these terms. 